2012

\title{
Student voice and engagement: connecting through partnership
}

Swain, J

http://hdl.handle.net/10026.1/12191

University of Plymouth

All content in PEARL is protected by copyright law. Author manuscripts are made available in accordance with publisher policies. Please cite only the published version using the details provided on the item record or document. In the absence of an open licence (e.g. Creative Commons), permissions for further reuse of content should be sought from the publisher or author. 


\section{Student voice and engagement: connecting through partnership}

\section{Claire Gray, Julie Swain \& Sue Rodway-Dyer}

To cite this article: Claire Gray, Julie Swain \& Sue Rodway-Dyer (2014) Student voice and engagement: connecting through partnership, Tertiary Education and Management, 20:1, 57-71, DOI: $10.1080 / 13583883.2013 .878852$

To link to this article: http://dx.doi.org/10.1080/13583883.2013.878852

Published online: 10 Feb 2014.

Submit your article to this journal $\widetilde{ }$

Џ Article views: 275

Q View related articles ¿

View Crossmark data ¿ 


\title{
Student voice and engagement: connecting through partnership
}

\author{
Claire Gray $^{\mathrm{a} *}$, Julie Swain ${ }^{\mathrm{a}}$ and Sue Rodway-Dyer ${ }^{\mathrm{b}}$ \\ ${ }^{a}$ Academic Partnerships, Plymouth University, Plymouth, UK; ${ }^{b}$ Academic Services, University of \\ Exeter, Falmouth, UK
}

(Received 22 October 2013; accepted 20 December 2013)

\begin{abstract}
This paper draws on research conducted across an English higher education partnership to investigate the ways in which student voice was engaged in further education colleges offering university awards through partnership arrangements. Such collaborations are characterised by the marginal presence of higher education students in an environment that is dominated by further education structures, culture and practice. This provides challenges for both colleges and universities in developing higher education student identity and appropriate mechanisms of student engagement that comply with expectations within the higher education sector but also recognise the contextual situation of students within the college environment. It is argued that student partnership collaboration can be a positive driver in an increasingly marketised global environment, where student voice and feedback mechanisms are at the forefront of quality assessments and institutional reputation. An ideal types framework is suggested as a heuristic device for the evaluation of college strategies of engagement.
\end{abstract}

Keywords: student experience; higher education in further education; feedback; student identity; ideal types

\section{Introduction}

The massification of higher education (Scott, 1995) has presented global challenges on how higher education is provided, managed and funded within a quasi-marketised system (Brown, 2011; Brown \& Carasso, 2013; Brown \& Scott, 2009). One dimension of this challenge is the management of wider access to higher education associated with the development of vocational routes (Robertson, 2002) to increase access and participation. Articulated in England and Wales through the provision of sub-degree higher education, including foundation degrees, large numbers of students experience this delivered in partnership with further education colleges (Higher Education Funding Council for England, 2003, 2010). English further education colleges offer a diverse range of post-compulsory education, which increasingly includes some aspects of vocational compulsory education as well as higher education in partnership with universities, national awarding bodies and professional bodies. Often equated with Australian technical and further education colleges (Wheelahan, 2009), further education colleges are portrayed as offering vocational and technical opportunities to those who did not succeed at school (Bathmaker \& Avis, 2005), as well as the more conventional post-compulsory routes to higher education.

\footnotetext{
*Corresponding author. Email: claire.gray@plymouth.ac.uk
} 
The culture and environment within colleges are often cited as providing a more personalised student learning experience, rooted in the needs of local learners and employers (Parry, Scott, Callender, \& Temple, 2012). Whilst acknowledging sectoral divergence, colleges are expected to adhere to academic standards and learning opportunities of equivalence within conventional higher education settings. Such equivalence is defined, measured and framed around the higher education institutions where awards are validated.

The assumptive architecture (Parry, 2009) of higher education has created variegated environmental conditions and experiences for students and staff within colleges, predicated on the structural assumptions of difference between further education and higher education (Bathmaker, Brooks, Parry, \& Smith, 2008; Parry, 2009). However, validating higher education institutions requires adherence to their own expectations of student experience, which are comparable with local quality processes and environments. This dialectic creates tension within the college environment, where operational structures are based on further education requirements, yet the basis of higher education provision is subject to contrasting expectations - the hallmark of a dual-sector institution (Garrod \& Macfarlane, 2007). This poses questions on the potential difficulties in the generation of higher education student identity, and the development of agency for students caught within this hinterland.

The question can be distilled into enquiry focussed on how colleges foster and hear the higher education student voice. College students are part of a national higher education system, but, within a cultural and institutional aegis dominated by the volume and practice of further education (Scott, 2009), their practice happens on the margins of the higher education sector. Literature on the student voice (Faux, McFarlane, Roche, \& Facer, 2006; Seale, 2010) points to progressive ways that it is heard and used to empower students in schools and further education environments, in contrast to practice in higher education institutions (Seale, 2010). The research discussed in this paper has investigated how the higher education student voice is articulated, heard and managed within colleges. An analytical model has been developed using a Weberian 'ideal types' approach to classify, define and categorise how different colleges manage higher education student voice.

\section{Context}

The empirical research was conducted in a large collaborative partnership in England with varying degrees of college size and higher education history. The partnership has grown from ca. 450 students in 1989 to over 10,000 students now studying validated university programmes. A particular aspect of the partnership has been in the acknowledgement that the students who work towards higher education awards in the colleges are recognised as students of the university, and can choose to engage with college and university representation. This is demonstrated by the appointment of university staff with a particular remit to work with college higher education students through the local student union. Within the partnership, there has been recognition of shared community engagements, which draw together actors with academic interests and identities (Gale, Turner, \& McKenzie, 2011; Turner, McKenzie, \& Stone, 2009). There have been a number of communities established to unite staff with common functional and academic interests, supporting a more collegiate understanding of college higher education student needs.

Significant investment has been made in working with the student union in providing a full-time officer responsible for college students, and designating the deputy 
president as a partnership-focussed position. Additional investment has been made in mechanisms designed to engage the student participation, including the appointment of paid representatives supporting elected course representatives liaising with the student union officers in quality assurance, representation and advocacy capacities. These roles have acted to 'bridge' between colleges, university and student union, creating a channel to disseminate information and facilitate student participation with issues of curriculum and governance. However, the anecdotal evidence to date is that, despite a concerted effort to engage students in the wider higher education community, there is still capacity for development. This research aimed to investigate this system, its functions and the development of an online community designed to support a dispersed college network.

In this enquiry, we investigated the student system within colleges, which literature suggests is an environment more conducive to clarity of purpose and function for learner voice (Faux et al., 2006; Seale, 2010). Additionally, the work arose out of the need for increased participation in official higher education student voice mechanisms, including the national student survey (NSS) within further education colleges offering higher education as a national indicator for quality monitoring. A key concern was how the university could utilise college structures whilst developing awareness of, and engagement with, university-based activity and communities. Such practice has been identified by Kezar (2005) as a significant factor in successful higher education student engagement.

Another aim was to develop a 'virtual voice' (VV), in essence a central community hub accessible anytime, anyplace, with any device, by all students regardless of location. Recognition of the primacy of student voice in the higher education quality cycle was a core aspect of this project, and attempting to implement immediate awareness-raising of its importance to encourage greater student participation. Communities can develop from initial face-to-face interactions, fostering an inclusive and shared environment and then evolved online (Wenger, 2006). The VV offers students wider opportunities for sharing activities and examples of good practice, where they have engaged with and influenced curriculum change through local collaborative voice. This virtual community was designed with students to act as a platform for shared understanding of the purpose of the higher education learner voice.

In addition, the community aimed to enable opportunities for student integration within a larger network, positively shaping community identity and empowerment. Witt, McDermott, Peters, and Stone (2007) argue that communities of practice, being groups of people who share a concern or a passion for something they do and learn how to do it better, form relationships to enable learning practice derived from community interactions. Support through virtual communities should enable students to share and learn through regular interaction, developing ownership and sharing knowledge and practice (Wenger, 2006). It was envisaged that this approach would be used amongst a wider student consultative community, exploring and adopting methodologies for communication and subsequent dissemination.

\section{The student voice}

Faux et al. (2006) refer to student voice as a process leading to empowerment through active engagement with those in positions of power. Bergan (2003) highlighted that whilst previous generations of students fought for representation, there is a perception that current students eschew the rights gained. This suggests a need to investigate whether this is a matter of perception or practice. Additionally, systematic institution-wide student 
feedback has become a crucial activity within universities, with the aim of extolling student feedback for wider consumption. The process of gaining feedback from students, in most institutions, has tended to take the form of questionnaires (Trowler \& Trowler, 2010) or focus groups, with a preoccupation with satisfaction (Grebennikov \& Shah, 2013; Harvey, 2001). Of growing importance in the UK is the NSS, which aims to provide feedback on the quality of the complete student educational experience, encompassing both higher education institutions and further education colleges. This has led many academics and universities to work at addressing the needs of the current diverse and large student body (Ramsden, 2008). Indeed, Nair and Shah (2011) believe that, in Australia, the practice of rewarding high levels of student satisfaction is used to measure educational quality and consistent performance, developing a robust student feedback and improvement framework.

Recent studies on the student voice within higher education tend to be descriptive and indicate huge variance, from reports on students at programme level (Hart \& Rush, 2007) to degree level (Hampton \& Blythman, 2006), and from learning experiences (O’Neill \& Wyness, 2005) to professional development planning (Brett, Lawton, \& Purnell, 2006). Seale (2010) identifies disparity between the ways that school and college contexts relate to student voice in comparison to higher education contexts. In higher education, quality enhancement and professional development are the key purposes for researching student experience, as opposed to governance, representation and rights, which are also prevailing themes within the school sector.

Gunter and Thomson (2007) present the view that the student voice involves tackling political processes via mechanisms of inclusion for both students and teachers. Faux et al. (2006) contend that school/college students have been empowered to express views regarding their learning experiences as partners in education, whilst Taylor and Robinson (2009) call for theoretical notions of power to be considered in relation to the development and understanding of the student voice. Walker and Logan (2008) outline the impact of statutory requirements on student voice, whilst noting the growth in awareness and positive engagement across educational sectors. The common thread that links this research is that students are more engaged if they are able to participate in key decisions about the context and content of their learning (Bergan, 2003; Campbell, Beasley, Beasley, \& Rumpus, 2007; Nair \& Shah, 2011). For this to occur in reality, staff need to listen to the student voice and allow them to become co-creators of their curriculum.

Research has highlighted that the student voice, although listened to, does not always directly relate to change within teaching practices and policies (Bovill, Cook-Sather, \& Felton, 2010; Harvey, 2001; Shah \& Nair, 2009). Bovill et al. (2010) believe that not only should staff consult with students, but they should be 'full participants in the design of teaching approaches, courses and curricula' (Bovill et al., 2010 , p. 133). Students, as members of the academic community, can be classed as stakeholders and therefore share a responsibility for their education with the framework of the institution (Bergan, 2003). This also forms part of the emerging discourse of student engagement with curriculum planning, design and development, as illustrated through national agendas (Quality Assurance Agency, 2013). However, at present, this is in its infancy and culture changes which can support the development of equality and empowerment take time for embedding.

Within education, student voice is considered crucial to success, which necessitates an active student role in the deeper learning process. To identify the factors for supporting the learner-centred approach, student voice research has mainly concentrated 
on understanding the student's perspective and learning experiences (Campbell et al., 2007). Seale (2010) identified common themes:

- asking questions about student experiences;

- seeing and understanding the student perspective;

- reflecting on implications for practice;

- hearing or listening to previously inaudible or ignored voices.

Seale (2010) demonstrated that by using a participatory methods approach, there is increased potential to empower students, whilst creating a trusting relationship between staff and students. Simple research techniques gave students choice in methods, control through editing and validation, and an influence over the presentation and dissemination of their experiences. This allows for the creation of highly personal stories which reiterate factors helping and hindering learning. Much research is qualitative in nature, often based on case studies (Seale, 2010), gathering students' perceptions and opinions through narrative and highly personalised accounts.

Bovill et al. (2010) reinforce national preoccupations with feedback, and suggest that successful student voice strategies require four approaches in integrating and engaging stakeholders to share in responsibility for analysing and designing pedagogical practices:

(1) Students as partners: students act as active and authoritative collaborators with academic staff in pedagogical planning, so that traditional hierarchies and roles are challenged.

(2) Support dialogue: dialogue can cross differences of position and perspective in teaching and learning, which will allow for fresh insights and deeper engagement.

(3) Foster collaboration: both academic staff and students take more responsibility and adopt new views of both for teaching and learning.

(4) Act as intermediaries: facilitating new relationships between academic staff and students.

Such democratic pedagogy may mean an uncomfortable but necessary change in power relations, and can create the need for re-thinking time investments. However, in the long term, it can be argued that the result is time savings through active learning processes (Wolf-Wendel, Ward, \& Kinzie, 2009). There is also need for academic developers to assist and work with the disciplinary differences to meet professional requirements, and provide opportunities for a visible democratic approach sharing responsibility (Beetham, McGill, \& Littlejohn, 2009; Bovill et al., 2010; Fielding, 2004). Within the prevailing assumptive architecture of higher education and further education partnership, it could be argued that there is an unexplored territory characterised by ambiguity in terms of boundaries and responsibilities, which is the focus of this research.

\section{Student learning experiences}

Increasing diversity of the student population over the last 20 years has changed the student profile (Sellar \& Gale, 2011), with many now working part-time, living at home or commuting to study, sometimes based in the workplace, and learning via 
technologies (Salmon, 2011). Most institutions now utilise more technological learning tools (accessible remotely) to enhance and support learning services and facilities (Nair \& Shah, 2011; Ramsden, 2008). Yet, there are issues with the learner experience of e-learning (Creanor, Gowan, Howells, \& Trinder, 2006) for students who are international, commuter, part-time, returning or from low-income or first-generation backgrounds, who can experience negative engagement due to feelings of isolation and environmental change (Christie, Munro, \& Wager, 2005). Despite these challenges, e-pedagogies represent a potentially beneficial opportunity for such 'non-traditional' students (Brett et al., 2006; Trowler \& Trowler, 2010).

Establishing shared understanding between students within colleges has been conceptualised through this to ensure that student experiences are comparable across environments (Nair \& Shah, 2011). As already discussed, colleges are often associated with low socio-economic student profiles and widening participation activity (Higher Education Funding Council for England, 2012). This brings into focus the necessity for active engagement by higher education partnerships to support both staff and students in this arena.

The way that student voice is perceived depends upon factors such as history, legacy, policy developments and the strategy within individual institutions. In this sense, there is a lack of congruence in the way in which the student voice is heard and interpreted across the divergent sector. To some, this concept is about the development of an institutional profile which will have national recruitment implications, whilst for others it is an inclusive mechanism which aims to address personalised student learning and is a progressive force for change.

Naidoo adopts a critical perspective on student voice and challenges the way in which the former iteration is used as part of the commodification of higher education (Naidoo, 2003). There is much work to do in the broader field of understanding the role of higher education and the university (Barnett, 1990), and in particular there is a need to understand the different ways in which student voice is used and the motivations behind their application (Seale, 2010). Consequently, this research attempted to engage with both conceptions of the value of student voice, as both mechanism for national metrics and also as an educational tool for enhancement of the inclusive and distinct college student experience.

\section{Methods}

The foundation of this research is a desire to engage with student voices within their learning contexts. An inductive approach and mixed methods enabled the voices to emerge in an open and supportive environment, guided by the desire for students to 'set the agenda' and determine what was important to them across the college community. We were interested in enabling students to identify their feelings of being college higher education students, and issues of identity and agency, which could provide a basis for engagement with governance and management within their college. The main tools employed to collect the data for this project were focus groups, observation and participation in student meetings, and interviews with appropriate actors supporting student voice.

Focus groups provided the best opportunity to maximise the numbers of students involved, and gather data that provided depth of discussion as well as breadth of student opinion. As this work was core to the development of an e-resource through community engagement, the focus groups were held early within the academic year when student 
representative meetings were in progress, aligning with the student representative cycle (Morgan, 1998; Silverman, 2011; Smithson, 2000). Three focus groups with college course representatives and two focus groups with faculty representatives were conducted.

Additional data were drawn from six interviews with college academic and support staff holding specific student voice responsibilities. The respondents were selected according to criteria that demonstrated a high level of connectivity with student voice and representation. Subsequently, three focus groups were conducted with college course representatives, affording the opportunity to engage and observe a wider student body within college environments. These focus groups had a dual purpose, and were formed around the college-led student representative meetings, enabling the researchers to observe processes of college-led student voice engagement. These discussions focused on the current activities within each college and opened opportunities for dialogue around specific university-led agendas, including NSS.

All data were transcribed and a thematic analysis was conducted from the focus groups and interviews (Bryman, 2008). Notes were taken from the researcher's observations of the college-led student voice meetings, which were collated and mapped against the thematic analysis from the interviews and focus groups. Reflective analysis (Charmaz, 2006) was employed to capture a narrative account of the observations made by the researchers as part of the project to promote student voice, contextualising aspects of the research and development of subsequent theoretical conceptualisations. Themes were identified and used to inform and build the virtual community, along with the research findings, aligning with Seale's (2010) approach of participatory engagement in student voice work. By engaging students, we were able to plan, explore, pilot and evaluate potential models of student voice articulation across student communities. An additional element to the data collected was in the form of day-to-day monitoring and evaluation of discussions, activities and threads from the online community.

\section{Project findings and respondent data}

An emergent issue from the focus groups was the misconceptions of the mechanics of the partnership and award arrangements. Many representatives displayed uncertainty over the nature of the relationship between the awarding body and the college, not realising that they would receive a university award and were part of a larger community:

I did not realise my college was part of a large partnership ... what an opportunity to link to other students studying the same things. (Student A)

Wow - I did not know how big the partnership is ... I could meet other students studying $\mathrm{x}$, that would be really useful. (Student $\mathrm{G}$ )

Yet, others overtly identified themselves as 'university students', which has been highlighted in other studies in this field (Christie, Tett, Cree, Hounsell, \& McCune, 2008):

I am at uni but know I won't be on the main campus until my top up year. (Student D)

It may not be surprising that students do not have high levels of awareness of partnership arrangements, but evidence suggests (Parry et al., 2012) that some college higher education students have been under the impression that they would be studying at a university rather than a college offering university-level qualifications: 
We thought our degree was from college X ... I did not realise it was awarded through university X ... I did not realise the connection. (Student B)

This suggests that there is evidence of a lack of clarity for some students in the way that colleges market their higher education awards, which is not necessarily allayed when studies commence. Given the increasing focus in the field of identity, this raises questions about how college higher education students view their entitlements and expectations, as students of both college (teaching and environment) and university (award and additional higher education resources). Alternatively, some students are able to articulate their decisions with clear reference to the university-college relationship:

I have chosen to study higher education within a college as it is the course I want to do and I can stay at home yet it gives me the opportunity to 'top up' in my third year. (Student C)

Students within this partnership are provided with a high level of university-branded merchandise on induction, and have access to university e-resources and additional materials tailored for off-campus access (to ease navigation between systems). Despite this high visibility, there emerged from the majority of respondents a palpable lack of awareness of what this meant for individual students and their entitlements and access to the university:

We get lots of information given to us from different places especially at the beginning of term which is really confusing. (Student $\mathrm{H}$ )

We argue that this may have significant effects for both identity and voice.

Respondents in this study seemed unaware of the significance of the NSS despite being elected representatives, and arguably the most engaged student groups. With the number of quantitative and often electronic student surveys being conducted on both college and university-based cohorts, the value and import of the NSS was 'lost' within survey fatigue. It became clear that the role of the NSS within national university rankings was not appreciated by students (Rodgers, Freeman, Williams, \& Kane, 2011). In all of the focus groups, there was a perceptible and almost universal shift to an appreciation of the value of NSS when this aspect of the survey was discussed.

Further detailed discussion on the NSS in the focus groups held at the university uncovered a lack of understanding of the questions, and in particular the contextual aspects of these questions for college higher education. Question 7 in the NSS asks whether feedback on work has been prompt. Many students were not aware of the university policy on the return of coursework, which altered their understanding of 'prompt'. Many colleges return coursework much faster than university expectations, but students used to a further education culture may not appreciate this, which is not always possible, or indeed the norm, for higher education work. Equivalence with other students on university awards, and not the college institutional expectation, is the focus of this question, which is generally not appreciated by college higher education students.

Within this theme, there was confusion for the students relating to questions on learning resources. Some interpreted the NSS questions as directed at the services provided by the university, rather than the combination of college and university resources. This was manifested by a general confusion and lack of clarity about 'whose' 
services and resources were under question. This was mirrored by questions on student union engagement, illustrating the extent of confusion over entitlement rights and identity.

The overriding impression across all respondents was that there appeared to be uncertainty in awareness-raising of the NSS. There was a strong perception that teaching staff who generally administered the survey were unaware of its importance, and were not able to clarify student misconceptions over the survey. This suggests a lack of institutional awareness in terms of strategy and dissemination. Arguably, this indicates a mismatch of purpose and intent creating an implementation vacuum. The potential implications for identity and ownership of the student voice that this raises are discussed later.

As part of this project, a pilot e-resource (discussed above) was developed and shared, using the student union officer and the academic staff member responsible for technology-enhanced learning across the partnership. Initially, activity was high as users were registering, entering profiles and contributing through posting, followed by a more tempered pace. However, many indicated that they used the site to keep abreast of notifications and other postings, whilst not always responding. When a 'hot topic' emerged at any stage of the academic cycle, such as the NSS, activity and interaction increased accordingly. One of the notable features of these interactions saw the identification of shared issues and practice, followed by potential resolution strategies, one of the project's original aims in the development of an online community.

Feedback from the end of this project suggests that the representatives have benefited hugely from engagement with the university via a community virtual voice in terms of their identification with the university:

I feel more part of the main campus through using the virtual voice. (Student E)

There were, however, some concerns over who might access the VV, in particular the potential for college staff to monitor the site:

Who will have access to this ... will our tutors be monitoring us? (Student B)

An important aspect within the project development was to assuage such concerns and impart control and ownership of the e-resource to the student body. As the project developed questions posed around the NSS, this gave opportunity to raise awareness, clarify concerns and share success stories. This was subsequently disseminated within the colleges through the course representatives which fed into wider college student forums:

We often just talk about negative things in course rep meetings and need to focus on good things as well. (Student I)

The representatives then focussed on the potential of the e-resource and identified what they felt they would need to share practice in two key areas, communication and technical. Resources were developed across communities, both internally within the colleges and through the virtual voice, to engage the wider student body. The representatives reported they felt more 'aware', 'prepared' and 'engaged', as they could see the impact of their collaborative work within student voice activity:

This has certainly made me more aware of my role as a student rep. (Student C) 
In relation to NSS, the representatives reported that their engagement with the VV led to a positive result in developing awareness and understanding of the survey. A richer picture of entitlement, expectation and engagement had emerged through the participative exploitation of the potential power of the student virtual voice. In one college, the NSS response rate stood at $10.03 \%$ mid-survey the year before, as opposed to a rate of $65.76 \%$ this year.

\section{Analysis}

Through engaging students and raising awareness and understanding of the importance of the NSS, notable results became evident. Many of the students felt empowered to work collaboratively at university and college levels. At the most pro-active end of the scale, this saw the development of many materials and videos, created and owned by students and shared through the virtual voice.

We would argue that the success of this has been evidenced by an increase in the response rates of the NSS, and most significantly with those from the colleges that engaged with the VV:

This gives us a great opportunity to share ideas and practice. (Student E)

I now feel part of a bigger group - even though I am not studying at the same campus. (Student F)

I did not know a lot this stuff before today ... at least I can go back and share with my class mates. (Student G)

Where tutors worked with students to discuss types of feedback, this demonstrated the potential to re-enforce its importance to their everyday learning experiences. The example of the NSS demonstrated the significance of active student engagement in areas that were not clearly defined or owned as college or university processes. In addressing this particular area and ownership, some colleges reaped enormous benefit in terms of active improvements in participation and positive results. Other colleges did not feel able to, or did not want to, hand over control to students in a format that was congruent with their status as higher education students. This in itself is probably the most interesting aspect to our analysis of the college higher education student voice.

The literature that points to the progressive aspects of school and college student voice work is set in environments where there is no duality of system, and there can be assumed to be a clear purpose, mission and rationale to the level of provision and expectations of students (Wheelahan, 2009). For college higher education, this is not the case, and we argue that identification of student voice in this context also prompts questions of language; for college higher education students the dominant voice is further education. Expectations for higher education students to take the next step in their journey to a more autonomous and self-directed mode of action are difficult in contexts that are not aware of the impact that duality can cause (Lea \& Simmons, 2012). This, however, produces an environment where ambiguity for higher education staff (Turner et al., 2009; Wilson \& Wilson, 2011) and students permeates expectation and entitlement. Identity becomes confused and students are unsure which language they should be using.

The mechanisms and infrastructure for an engaged and empowered higher education student voice within the college environment may be hard to nurture, particularly in environments where there is small and dispersed higher education provision. The value 
of tools such as the VV is in connecting students across such environments, so that they start to gain a communal conceptualisation of the language of higher education and the institutional mechanisms for nurture within college environments.

Using a grounded approach (Charmaz, 2006) to the analysis of the data provided an opportunity to conceptualise the behaviours and attitudes that were exhibited across different college environments. Whilst observing and analysing what can be classified as naturally occurring data as part of student voice work, and using this in conjunction with student participation, we have been able to generate a framework that can typify the management and development of higher education student voice. The development of ideal types has been used here as a device to evaluate the contextual appreciation of how student voice can be articulated within college higher education contexts. It does not intend to represent the characteristics or circumstances of particular colleges, but draws on empirical and observational findings to illustrate contrasting approaches, observed in student voice engagement. 'Ideal types', associated with Weber (Hekman, 1983; Weber, 1949), are used here as heuristic devices to encapsulate potential models of social action to help position or define categories of behaviour. Three ideal types of institutional behaviour are proposed:

1. Disengaged: This behaviour and action is illustrated by a lack of clarity of expectations of roles and responsibilities for higher education students. This leads to vacuums which are erratically filled, suggesting that there is no parity or consistency of approach across higher education students in the college. Lack of understanding as an institution, and of the necessary vision and structure to create this environment, is a characteristic of this type. One person may be trying to lead developments on their own, which makes any attempts disjointed, segmented and eclectic. This is typified in situations where students are unable to make connections between the values of higher education and the lived experience of study within the college environment. In such cases, there is no collective and congruent vision of higher education identity.

2. Controlled: This behaviour is characterised by a dominant further education culture, where students may be told that they are expected to participate and instructed on the types of things to say and how to say it. Action is therefore expected to be college-owned and student voice is passive and compliant. College institutional voice and process dominate. There is a lack of cohesive ownership and responsibility for higher education students at a higher level of management. Higher education identity is managed as college identity, and voice is a function that occurs without the autonomy associated with higher education students. This differs from the disengaged type in terms of there being a clear institutional vision for higher education student identity, but subsumed within a dominant further education context, led and managed within this aegis.

3. Empowered: There is a clear and transparent buy-in from management to enable student voice at higher education to morph into a new and distinct entity from other student voice processes. Structure and defined responsibilities are discussed, and the student voice as part of the appropriate management process is negotiated. This is conceptualised as integral to the college higher education function and ethos in which partnership with students is equal. Bringing different shared responsibilities to the table and recognising the benefits of this, it empowers students to act in a collegiate fashion. Higher education activity is likely to be mature and well established in this environment, where higher education identity is integral to student experience. 
These three ideal types model behaviour and process that can provide a continuum by which to evaluate the progress of colleges in the development of higher education student voice. This demonstrates stages across the spectrum of engagement, signposting potential points of development in the management of student voice. The role that is played by the partner university, and their expectations to promote and support higher education student engagement, could be seen as an integral aspect to collaborative work. An example of the significance of this type of intervention is within the early induction period, where attempts are made to embed the conception of higher education student voice and university identity within college processes. As already noted, the maximisation of the success of this approach lies in the organisational buy-in and communication strategy across the college.

\section{Conclusion}

This research aimed to examine how college practice, which Scott (2009) identifies as being on the margins of mainstream higher education, can be captured as a more central activity within further education. As part of this research, it has become critical to illuminate the personalised approach embedded within the learning environment, and adopted by colleges to support successful student voice engagement. This research has exposed the challenges of capturing synergies between successful further education approaches aligned with higher education expectations within colleges.

Dependent on factors such as size, history and maturity, colleges will have variance in the existence and prominence of their student unions in terms of student voice activity. Within this research, the university student union played a pivotal role in developing student voice through institutional structures. Within individual colleges, higher education student voice could be described as marginalised, due to an embedded further education institutional culture and mission. If viewed as a network rather than a number of individual institutions, we argue that a stronger collegiate student voice could be heard:

I now feel part of a bigger group - even though I am not studying at the same campus. (Student F)

It feels like we have a joint voice and opinions which has allowed me to develop communications at my college. (Student $\mathrm{H}$ )

Findings from this research demonstrate that there are no clear benchmarks aligning activity within the college sector towards higher education practice. What has become evident is that colleges have developed individual student voice engagement strategies built from further education models (Faux et al., 2006). Whilst this has been proven as successful within further education, this research suggests there could be room for development congruent with higher education expectations, identity and practice. In recent years, the prominence of student voice has been elevated through policy developments and focus on quality measures for public information (including the introduction of the Key Information Set in 2012). This is a significant challenge to colleges, where the traditional strengths of personalised learning may not be reflected by NSS due to the methodology employed.

The evidence demonstrates that a shared mission and understanding is required from both university and college to enable a successful student voice to be heard. The ideal 
types proposed can be mapped to existing facets of individual college activity, providing a benchmark that could be aligned to strategy. Practice can be evolved from this evaluation and modelled accordingly to partnership developments and structures. This project has identified the potential of shared endeavour to develop an effective, open and honest higher education student identity and voice.

This research has indicated that students require further clarification and awareness on expectations and requirements to support and enhance the student experience within colleges. Within the data, a 'fuzziness' emerged regarding students' awareness of partnership arrangements, entitlement and identity. By connecting students across the colleges through the $\mathrm{VV}$, they seemed to position themselves within the wider arrangements with other colleges and the awarding university:

I feel more part of the main campus through using the virtual voice. (Student E)

With a greater focus on access to public information to facilitate student choice in higher education, this work has provided a concentration on some of the core issues. A valid representation is now required of the college higher education experience drawn from the collective student voice, with a greater comprehension of the identity and value of studying college higher education. Colleges need to frame the value and importance of student voice, and foster and nurture it within the higher education context and framework. Successful approaches are captured within this research that demonstrate the value of ownership and empowerment through investment in higher education student voice and identity.

\section{References}

Barnett, R. (1990). The idea of higher education. Buckingham: Open University Press.

Bathmaker, A.-M., \& Avis, J. (2005). Becoming a lecturer in further education in England: The construction of professional identity and the role of communities of practice. Journal of Education for Teaching: International Research and Pedagogy, 31, 47-62. doi:10.1080/ 02607470500043771

Bathmaker, A.-M., Brooks, G., Parry, G., \& Smith, D. (2008). Dual-sector further and higher education: Policies, organisations and students in transition. Research Papers in Education, 23, 125-137.

Beetham, H., McGill, L., \& Littlejohn, A. (2009). Thriving in the 21st century: Learning literacies for the digital age (LLiDA project): Executive summary. Conclusions and recommendations. Glasgow: The Caledonian Academy, Glasgow Caledonian University.

Bergan, S. (2003). Student participation in higher education governance. Strasbourg: Council of Europe.

Bovill, C., Cook-Sather, A., \& Felton, A. (2010). Students as co-creators of teaching approaches, course design, and curricula: Implications for academic developers. International Journal for Academic Development, 16, 133-145.

Brett, P., Lawton, M., \& Purnell, E. (2006). Student evaluation and the learner voice (Pathfinder project briefing paper 2 of 4). University of Wolverhampton. Retrieved from http://www2.wlv.ac.uk/celt/Projects/UoW\%20PF\%20briefing\%20paper\%202\%20student\%20voice.doc.

Brown, R. (Ed.). (2011). Higher education and the market. Abingdon: Routledge.

Brown, R., \& Carasso, H. (2013). Everything for sale? The marketisation of UK higher education. London: Routledge.

Brown, R., \& Scott, P. (2009). The role of the market in higher education. Report for the Leadership Foundation for Higher Education. Retrieved March 10, 2010, from http:// www.lfhe.ac.uk/news/hedebate09.html

Bryman, A. (2008). Social research methods (3rd ed.). Oxford: Oxford University Press. 
Campbell, F., Beasley, L., Eland, J., \& Rumpus, A. (2007). Hearing the student voice: Promoting and encouraging the effective use of the student voice to enhance professional development in learning, teaching and assessment within higher education. Report for HEA Escalate. Retrived May 15, 2010, from http://dera.ioe.ac.uk/13053/2/3911.pdf

Charmaz, K. (2006). Constructing grounded theory. London: Sage.

Christie, H., Munro, M., \& Wager, F. (2005). 'Day students' in higher education: Widening access students and successful transitions to university life. International Studies in Sociology of Education, 15, 3-30.

Christie, H., Tett, L., Cree, V. E., Hounsell, J., \& McCune, V. (2008). 'A real rollercoaster of confidence and emotions': Learning to be a university student. Studies in Higher Education, 33, 567-581. doi:10.1080/03075070802373040

Creanor, L., Gowan, D., Howells, C., \& Trinder, K. (2006). The learner's voice: A focus on the e-learner experience. LEX Project. JISC. Retrived May 15, 2010, from http://www.jisc.ac.uk/ whatwedo/programmes/elearningpedagogy/elearningexperts/feb06.aspx

Faux, F., McFarlane, A., Roche, N., \& Facer, K. (2006). Research publications: Listening to the learner. Bristol: Future Lab Publications.

Fielding, M. (2004). Transformative approaches to student voice: Theoretical underpinnings, recalcitrant realities. British Educational Research Journal, 30, 295-311.

Gale, K., Turner, R., \& McKenzie, L. M. (2011). Communities of praxis? Scholarship and practice styles of the HE in FE professional. Journal of Vocational Education \& Training, 63, $159-169$.

Garrod, N., \& Macfarlane, B. (2007). Scoping the duals: Structural challenges of combining further and higher education in post-secondary institutions. Higher Education Quarterly, 61, 578-596.

Grebennikov, L., \& Shah, M. (2013). Monitoring trends in student satisfaction. Tertiary Education and Management, 19, 301-322. doi:10.1080/13583883.2013.804114

Gunter, H., \& Thomson, P. (2007). Learning about student voice. Support for Learning, 22, $181-188$.

Hampton, D., \& Blythman, M. (Eds.). (2006). Recovering the student voice: Retention and achievement on foundation degrees. London: FDF Publications.

Hart, M., \& Rush, R. (2007). E-learning and the development of 'voice' in business studies education. International Journal of Educational Management, 21, 68-77.

Harvey, L. (2001). Student feedback: A report to the higher education funding council for England. Bristol: HEFCE.

Hekman, S. J. (1983). Weber's ideal type: A contemporary reassessment. Polity, 16, 119-137.

Higher Education Funding Council for England. (2003). Foundation degrees. Invitation to bid for additional places and development funds 2004-05 (2003/48). Bristol: Author.

Higher Education Funding Council for England. (2010). Foundation degrees key statistics 2001-02 to 2009-10. Bristol: Author.

Higher Education Funding Council for England. (2012). Widening participation and non-continuation indicators for further education colleges. Bristol: Author.

Kezar, A. (2005). Promoting student success: The importance of shared leadership and collaboration. Occasional Paper No. 4. Bloomington, IN: National Survey of Student Engagement.

Lea, J., \& Simmons, J. (2012). Higher education in further education: Capturing and promoting HEness. Research in Post-Compulsory Education, 17, 179-193. doi:10.1080/ 13596748.2012.673888

Morgan, D. L. (1998). Planning focus groups. London: Sage.

Naidoo, R. (2003). Repositioning higher education as a global commodity: Opportunities and challenges for future sociology of education work. British Journal of Sociology of Education, 24, 249-259.

Nair, C. S., \& Shah, M. (2011, June 29-July 1). Developing an effective student feedback and improvement system: Exemplars with proven success. Paper presented at the Australian Universities Quality Forum, Demonstrating Quality, Melbourne.

O'Neill, B. J., \& Wyness, M. A. (2005). Student voices on an interprofessional course. Medical Teacher, 27, 433-438.

Parry, G. (2009). Higher education, further education and the English experiment. Higher Education Quarterly, 63, 322-342. 
Parry, G., Scott, P., Callender, C., \& Temple, P. (2012). Understanding higher education in further education colleges. Research paper number 69. London: Department for Business, Innovation and Skills.

QAA. (2013). Higher education review: A handbook for providers. Gloucester: Author.

Ramsden, P. (2008). The future of higher education. Teaching and the student experience. Department for Business, Innovation and Skills. Retrived May 15, 2010, from http://webarchive.nationalarchives.gov.uk/+/http://www.bis.gov.uk/wp-content/uploads/2009/10/ HE-Teaching-Student-Experience.pdf

Robertson, D. (2002). Intermediate-level qualifications in higher education: An international assessment. A report to the HEFCE. Bristol: HEFCE.

Rodgers, T., Freeman, R., Williams, J., \& Kane, D. (2011). Students and the governance of higher education: A UK perspective. Tertiary Education and Management, 17, 247-260. doi: $10.1080 / 13583883.2011 .586046$

Salmon, G. (2011). E-moderating (3rd ed.). London: Routledge.

Scott, P. (1995). The meanings of mass higher education. Buckingham: Open University Press.

Scott, P. (2009). On the margins or moving into the mainstream? Higher education in further education in England. Higher Education Quarterly, 63, 402-418.

Seale, J. (2010). Doing student voice work in higher education: An exploration of the value of participatory methods. British Educational Research Journal, 36, 995-1015.

Sellar, S., \& Gale, T. (2011). Mobility, aspiration, voice: A new structure of feeling for student equity in higher education. Critical Studies in Education, 52, 115-134. doi:10.1080/ 17508487.2011 .572826

Shah, M., \& Nair, C. S. (2009). Using student voice to improve student satisfaction: Two Australian universities the same agenda. Journal of Institutional Research (South East Asia), $7,43-55$.

Silverman, D. (2011). Interpreting qualitative data (4th ed.). London: Sage.

Smithson, J. (2000). Using and analysing focus groups: Limitations and possibilities. International Journal of Social Research Methodology, 3, 103-119. doi:10.1080/136455700405172

Taylor, C., \& Robinson, C. (2009). Student voice: Theorising power and participation. Pedagogy, Culture \& Society, 17, 161-175.

Trowler, V., \& Trowler, P. (2010). Student engagement evidence summary: Deliverable 2 for the Higher Education Academy student engagement project. Retrieved May 15, 2010, from http:// eprints.lancs.ac.uk/61680/1/Deliverable_2._Evidence_Summary._Nov_2010.pdf

Turner, R., McKenzie, L., \& Stone, M. (2009). Square peg - round hole: The emerging professional identities of HE in FE lecturers working in a partner college network in south-west England. Research in Post-Compulsory Education, 14, 355-368.

Walker, L., \& Logan, A. (2008). Learner engagement: A review of learner voice initiatives across the UK's education sectors. Bristol: Future Lab Publications.

Weber, M. (1949). The methodology of the social sciences. (E. A. Shils \& H. A. Finch, Trans.). New York, NY: Free Press.

Wenger, E. (2006). Communities of practice. Retrieved February 23, 2011, from http://www. ewenger.com/theory/index.htm

Wheelahan, L. (2009). Post-secondary education and social justice. In N. Garrod \& B. Macfarlane (Eds.), Challenging boundaries: Managing the integration of post-secondary education (pp. 29-44). Abingdon: Routledge.

Wilson, A., \& Wilson, B. (2011). Pedagogy of the repressed: Research and professionality within HE in FE. Research in Post-Compulsory Education, 16, 465-478. doi:10.1080/ 13596748.2011.627169

Witt, N., McDermott, A., Peters, M., \& Stone, M. (2007, December 2-5). A knowledge management approach to developing communities of practice amongst university and college staff. Paper presented at ICT: Providing choices for learners and learning, ASCILITE, Singapore.

Wolf-Wendel, L., Ward, K., \& Kinzie, J. (2009). A tangled web of terms: The overlap and unique contribution of involvement, engagement, and integration to understanding college student success. Journal of College Student Development, 50, 407-428. 